\title{
BMJ Open Association between caesarean section delivery and obesity in childhood: a longitudinal cohort study in Ireland
}

\author{
Gwinyai Masukume, ${ }^{1,2}$ Fergus P McCarthy, ${ }^{1,2,3}$ Philip N Baker, ${ }^{4}$ Louise C Kenny, ${ }^{5}$ \\ Susan MB Morton, ${ }^{6}$ Deirdre M Murray, ${ }^{1,7}$ Jonathan O'B Hourihane, ${ }^{1,7}$ \\ Ali S Khashan ${ }^{1,8}$
}

To cite: Masukume G, McCarthy FP, Baker PN, et al. Association between caesarean section delivery and obesity in childhood: a longitudinal cohort study in Ireland. BMJ Open 2019;9:e025051. doi:10.1136/ bmjopen-2018-025051

- Prepublication history and additional material for this paper are available online. To view these files, please visit the journal online (http://dx.doi. org/10.1136/bmjopen-2018025051).

Received 2 July 2018

Revised 8 August 2018

Accepted 13 November 2018

Check for updates

(c) Author(s) (or their employer(s)) 2019. Re-use permitted under CC BY-NC. No commercial re-use. See rights and permissions. Published by BMJ.

For numbered affiliations see end of article.

Correspondence to Dr Fergus P McCarthy; fergus.mccarthy@ucc.ie

\section{ABSTRACT}

Objectives To investigate the association between caesarean section (CS) birth and body fat percentage $(\mathrm{BF} \%)$, body mass index (BMI) and being overweight or obese in early childhood.

Design Prospective longitudinal cohort study.

Setting Babies After Screening for Pregnancy Endpoints: Evaluating the Longitudinal Impact on Neurological and Nutritional Endpoints cohort.

Participants Infants born to mothers recruited from the Screening for Pregnancy Endpoints study, Cork University Maternity Hospital between November 2007 and February 2011.

Outcome measure Overweight or obese defined according to the International Obesity Task Force criteria. Results Of the 1305 infants, 362 (27.8\%) were delivered by CS. On regression analysis, $\mathrm{BF} \%$ at 2 months did not differ significantly by delivery mode. Infants born by CS had a higher mean BMl at 6 months compared with those born vaginally (adjusted mean difference $=0.24 ; 95 \% \mathrm{Cl}$ 0.06 to $0.41, p$ value $=0.009$ ). At 2 years, no difference was seen across the exposure groups in the risk of being overweight or obese. At 5 years, the association between prelabour CS and the risk of overweight or obesity was not statistically significant (adjusted relative risk ratio, aRRR=1.37; $95 \% \mathrm{Cl} 0.69$ to 2.69) and the association remained statistically nonsignificant when children who were macrosomic at birth were excluded from the model (aRRR=0.86; $95 \% \mathrm{Cl} 0.36$ to 2.08).

Conclusion At 6 months of age, children born by CS had a significantly higher BMI but this did not persist into future childhood. There was no evidence to support an association between mode of delivery and long-term risk of obesity in the child.

\section{INTRODUCTION}

Over recent decades, caesarean section (CS) rates have risen considerably worldwide and in some countries, CS rates now exceed $50 \%{ }^{1}$ The aetiology of the global CS rate increase is multifactorial and includes a decline in vaginal births after caesarean, physician fear of litigation, maternal request, more multiple pregnancies resulting from greater assisted
Strengths and limitations of this study

Data were obtained from a well-phenotyped contemporary prospective longitudinal cohort study.

- Body fat percentage was measured by air displacement plethysmography which is regarded as the gold standard method.

- A limitation was the unavailability of maternal pre-pregnancy body mass index.

- The number of overweight and obesity cases at 2 and 5 years of age was limited.

reproductive technology use and access to private health insurance. $^{2-7}$

Although a timely CS can be both necessary and life-saving, for example, in cases of obstructed labour, transverse lie and fetal distress/compromise, it nevertheless conveys complications. For the mother, these include an increased length of hospital stay, infection and haemorrhage, as well as a higher risk of respiratory complications in the infant and consequent admission to the neonatal intensive care unit. ${ }^{8}$

Birth weight is the most commonly used indicator of in utero growth; however, body composition at birth, the relative proportion of fat and fat-free mass can provide a more accurate picture. ${ }^{9}$ We have shown retrospectively that neonatal body fat percentage $(\mathrm{BF} \%)$ is more closely linked to risk of CS than birth weight. ${ }^{10}$ Therefore, conversely changes in $\mathrm{BF} \%$ could be an early and more sensitive indicator of future health. It has been hypothesised that the described association between abnormal birth weight and future cardiometabolic disease ${ }^{11}$ across the life course can be more closely attributed to differences in early life body composition than to birth weight differences. ${ }^{9}$

CS itself has been consistently associated with an increased risk of obesity later in life, although studies have been inconclusive. ${ }^{12-14}$ 
It is also unclear whether this increased risk pertains to elective/prelabour CS or emergency CS/CS in labour. Making this distinction is challenging because of limited literature so much so that the latest systematic review and meta-analysis on the topic (2018) performed an analysis including all CS and did not differentiate. ${ }^{15}$ Several research papers have been able to distinguish between elective and emergency CS but these have been limited by small sample sizes. ${ }^{16-18}$ With CS in labour, membranes are more likely to have ruptured, thereby exposing the infant to vaginal microflora. ${ }^{19}$ However, lack of exposure to the vaginal microflora among infants born by elective CS, where membranes are more likely to be intact, has been suggested as the main causal mechanism for the increased risk of obesity later in life. ${ }^{20-22}$ Some have disputed this ${ }^{23}{ }^{24}$; nevertheless, robust data from animal experiments demonstrate a potential causal role for CS delivery in the development of childhood obesity. ${ }^{25}$

Given the worldwide increase in nonmedically indicated prelabour $\mathrm{CS},{ }^{8}$ this type of CS represents a potentially modifiable risk factor for childhood obesity. The aim of this study was to investigate the relationship between CS delivery, particularly prelabour CS, and childhood body composition and growth, using a well-phenotyped prospective longitudinal birth cohort with detailed clinical phenotyping of both mothers and their children. We wanted, in particular, to examine the potential confounding effect of macrosomia, as this is both a risk factor for CS and for long-term obesity.

\section{METHODS}

\section{Data source and population sampled}

Data were obtained from the Irish cohort of the prospective Screening for Pregnancy Endpoints (SCOPE) study of 'low-risk' nulliparous women with singleton pregnancies (ACTRN12607000551493, www.scopestudy.net/) and its follow-up prospective Irish birth cohort, the Babies After SCOPE: Evaluating the Longitudinal Impact on Neurological and Nutritional Endpoints (BASELINE) study (NCT01498965, www.baselinestudy.net/).

The SCOPE and BASELINE study methodologies are reported in detail elsewhere. ${ }^{26}{ }^{27}$ Briefly, the aim of the SCOPE study was to develop screening approaches, clinical and molecular, to predict fetal growth restriction, pre-eclampsia and spontaneous preterm birth in healthy nulliparous women during early gestation. Exclusion criteria included the following: (1) considered to be at high risk of fetal growth restriction, pre-eclampsia or spontaneous preterm birth due to underlying medical conditions (chronic hypertension, diabetes, renal disease, systemic lupus erythematosus, anti-phospholipid syndrome, sickle cell disease, HIV), previous cervical knife cone biopsy,$\geq 3$ previous terminations or $\geq 3$ miscarriages, current ruptured membranes; (2) had a major uterine anomaly, a known major fetal anomaly or abnormal karyotype or (3) received an intervention that could modify pregnancy outcome (eg, aspirin therapy, cervical suture).
In brief, the BASELINE cohort participant's mothers were recruited at $15 \pm 1$ weeks of pregnancy from Cork University Maternity Hospital between November 2007 and February 2011. Of the 2579 women approached to participate, $1774(69 \%)$ gave their written informed consent. From those, 1537 (87\%) had infants recruited into the BASELINE study. The sociodemographic, lifestyle and physical measurements were collected by trained research midwives. A complete audit trial was available for the data that were entered into a centrally accessed internet database (MedSciNet AB, Stockholm, Sweden).

\section{Exposure and outcome ascertainment}

Delivery mode was grouped into four categories, namely unassisted vaginal delivery (VD), operative VD, prelabour lower segment (LS) CS and LSCS in labour. Operative VD constituted delivery by either vacuum extraction or forceps.

Whole body density was calculated from naked weight measured by an electronic scale (seca 384; seca, Birmingham, UK) to the nearest gram divided by body volume estimated by the PEA POD air displacement plethysmography system (COSMED, Concord, CA, USA) within the first 4 days of life and also at age 2 months. The PEA POD agrees highly with the gold standard four-compartment model and is noninvasive, fast and safe. ${ }^{10} 2829$

Based on body density and a two-compartment model of body composition (fat and fat-free mass), using values established by Fomon, ${ }^{28} \mathrm{BF} \%$, the primary outcome, was calculated as follows: ([fat mass, $\mathrm{kg}$ /body mass, $\mathrm{kg}] \times 100$ ).

The child's height and weight were measured by a trained interviewer using standardised protocols and medically approved instruments. At birth, 2 months, 6 months, 1 year, 2 years and 5 years of age, body mass index (BMI) in $\mathrm{kg} / \mathrm{m}^{2}$ was calculated for each child. At age 2 and 5 years, BMI was classified as thin, normal, overweight or obese, according to the International Obesity Task Force (IOTF) criteria. ${ }^{31}$ The IOTF classification begins at age 2 years.

The following potential confounders as reported in the literature $^{12-143233}$ were included a priori: maternal age, education, ethnicity, marital status, infant sex, maternal smoking during pregnancy, maternal BMI at the first antenatal visit, gestational age (at delivery), birth weight and pre-eclampsia. For instance, smoking cigarettes is a potential confounder because it is a risk factor for both CS birth ${ }^{34}$ and for childhood obesity. ${ }^{35}$

\section{Statistical analysis}

Stata V.14SE (StataCorp LP College Station, TX, USA) was used for statistical analysis. Categorical variables were described using frequency (n) and per cent (\%). Numeric variables were described using the mean (SD) or median (IQR).

Crude and adjusted linear regression models were used to examine the association between mode of delivery and $\mathrm{BF} \%$. Linear regression models were also used to evaluate 
the association between delivery mode and BMI as a continuous measure.

Crude and adjusted multinomial logistic regression models were used to examine the association between mode of delivery and the risk of being overweight or obese. Adjusted mean differences and adjusted relative risk ratios (aRRR), for the linear and multinomial logistic regression models, respectively, were calculated with $95 \%$ CIs. Unassisted VD was the reference category and normal BMI was the base outcome for the multinomial logistic regression models. Models were stratified by whether infants were macrosomic or not which was defined as a birth weight $>4000 \mathrm{~g}$ or $\leq 4000 \mathrm{~g}$, respectively. We also explored interaction by infant sex. Statistical significance was defined as a $\mathrm{p}<0.05$.

\section{Patient involvement}

Participants were not involved in establishing the research question, outcome measures including the study design and interpretation or writing of this paper. The results will be disseminated via the study website, social media, information evenings and by newsletter.

\section{RESULTS}

Of the 1305 infants, $943(72.3 \%)$ were delivered vaginally. The remainder of the deliveries $(27.8 \%)$ were by CS; prelabour LSCS (12.0\%) and LSCS in labour $(15.8 \%)$, respectively (table 1$)$. At birth, $13.0 \%$ of infants were macrosomic $(>4000 \mathrm{~g}) ; 11.0 \%$ were large for gestational age $(>90$ th percentile for customised birth weight centiles). At 2 years of age, $116(10.9 \%)$ children were overweight or obese (using IOTF cut-offs). At age 5 years, the respective number was $118(14.5 \%)$. At age 2 months, the mean $(\mathrm{SD}) \mathrm{BF} \%$ was calculated at $21.8 \%( \pm 4.3 \%)$. $\mathrm{BF} \%$ approximated to the normal distribution.

The average BMI, by the four birth modes, at each of the six time points is depicted in figure 1 and for all vaginal and $\mathrm{CS}$ births in figure 2 . The maximum divergence in BMI by delivery mode occurred at 6 months of age. At 6 months, the mean BMI of infants delivered vaginally and those born by CS was $17.3 \mathrm{~kg} / \mathrm{m}^{2}$ and $17.6 \mathrm{~kg} /$ $\mathrm{m}^{2}$, respectively.

Across delivery mode, missing data were distributed equally for the primary and secondary outcomes, $\mathrm{BF} \%$ and BMI, respectively. Thus, missing data were unlikely to have affected the results or conclusions (online supplementary table 1 ).

\section{Mode of delivery and BF\% at age 2 months}

At age 2 months, there was no association between prelabour $\mathrm{CS}$ and $\mathrm{BF} \%$ (adjusted $\mathrm{BF} \%$ mean difference $=0.46$; $95 \% \mathrm{CI}-0.46$ to 1.40 ) and LSCS in labour (adjusted BF\% mean difference $=0.07 ; 95 \%$ CI -0.88 to 0.73 ) in comparison to the reference group of children delivered by unassisted VD (table 2).

Mode of delivery and BMI at age 6 months, 2 years and 5 years Infants born by CS had a significantly higher mean BMI at 6 months compared with those born vaginally (adjusted BMI mean difference $=0.24 ; 95 \%$ CI 0.06 to $0.41, \mathrm{p}$ value $=0.009$ ). Limiting analysis to non-macrosomic infants resulted in an adjusted BMI mean difference $=0.26 ; 95 \%$ CI 0.07 to 0.45 , $\mathrm{p}$ value $=0.008$.

There was, however, no statistically significant differential effect by sex ( $p$ value for the interaction term was 0.70 ; online supplementary figure 1 ).

There was no statistically significant association between prelabour CS (aRRR=1.38; 95\% CI 0.73 to 2.62) or LSCS in labour (aRRR $=0.88 ; 95 \% \mathrm{CI} 0.48$ to 1.61 ) and the risk of being overweight or obese at age 2 years, as compared with the reference group (table 3). Limiting analysis to non-macrosomic infants at age 2 years resulted in the association between prelabour CS and the risk of overweight and obesity being $(\mathrm{aRRR}=0.95 ; 95 \%$ CI 0.44 to 2.05 ) and for LSCS in labour ( $\mathrm{aRRR}=0.89 ; 95 \%$ CI 0.44 to 1.82) (online supplementary table 2).

At age 5 years, there was a nonsignificant association between prelabour CS and the risk of being overweight or obese (aRRR=1.37; 95\% CI 0.69 to 2.69) (table 4). There was also no association between LSCS in labour and the risk of being overweight or obese $(\mathrm{aRRR}=1.69$; 95\% CI 0.92 to 3.08). Limiting analysis to non-macrosomic infants at age 5 years resulted in the association between prelabour CS and the risk of overweight and obesity being (aRRR $=0.86$; 95\% CI 0.36 to 2.08 ) and for LSCS in labour (aRRR=2.37; 95\% CI 1.19 to 4.68) (online supplementary table 3 ).

\section{DISCUSSION \\ Main findings}

There was no significant difference in $\mathrm{BF} \%$ at age 2 months between modes of delivery. A statistically significant difference in BMI at age 6 months was observed between infants born by CS and VD. Infants born by CS had a higher mean BMI. There was no evidence to support a link between prelabour CS and our secondary outcome, being overweight or obese, at 2 and 5 years of age.

\section{Strengths and limitations}

A major strength was the availability of data from a well-phenotyped prospective longitudinal cohort that is among those with the most data available for $\mathrm{BF} \%$. This allowed us to investigate the role of factors such as cigarette smoking prior to conception, which is often not available from prior or extant cohorts. In addition, we used robust measures of body composition obtained by air displacement plethysmography, which is regarded as the gold standard method.

A homogeneous sample where $98 \%$ of the cohort's participants were Caucasian, primiparous and 'low risk $^{, 27}$ could limit the generalisability of these findings to heterogeneous populations. However, the cohort reflected Ireland's demographics of reproductive age women (15-49years), where $93 \%$ are Caucasian women. ${ }^{36}$ The variable pre-pregnancy BMI was 
Table 1 Characteristics of the study population at 2 months

\begin{tabular}{|c|c|c|c|c|c|}
\hline Characteristic & $\begin{array}{l}\text { Overall } \\
\text { n (\%) }\end{array}$ & $\begin{array}{l}\text { Unassisted vaginal } \\
\text { n (\%) }\end{array}$ & $\begin{array}{l}\text { Operative vaginal * } \\
\text { n (\%) }\end{array}$ & $\begin{array}{l}\text { Prelabour LSCS } \\
\mathrm{n}(\%)\end{array}$ & $\begin{array}{l}\text { LSCS in labour } \\
\mathrm{n}(\%)\end{array}$ \\
\hline $\mathrm{N}$ & $1305(100)$ & $470(36.0)$ & $473(36.2)$ & $156(12.0)$ & 206 (15.8) \\
\hline $\begin{array}{l}\text { Maternal age (years), } \\
\text { median IQR }\end{array}$ & 30 (28-33) & 30 (27-32) & $30(28-33)$ & $32(29.5-34)$ & $31(29-33)$ \\
\hline$<20$ & $19(1.5)$ & $9(1.9)$ & $9(1.9)$ & $1(0.6)$ & $0(0.0)$ \\
\hline $20-24$ & $111(8.5)$ & $57(12.1)$ & $38(8.0)$ & $4(2.6)$ & $12(5.8)$ \\
\hline $30-34$ & $615(47.1)$ & $215(45.7)$ & $214(45.2)$ & $85(54.5)$ & $101(49.0)$ \\
\hline $35-39$ & $155(11.9)$ & $31(6.6)$ & $66(14.0)$ & $28(17.9)$ & $30(14.6)$ \\
\hline$\geq 40$ & $17(1.3)$ & $1(0.2)$ & $7(1.5)$ & $4(2.6)$ & $5(2.4)$ \\
\hline \multicolumn{6}{|l|}{ Ethnicity } \\
\hline Caucasian & 1287 (98.6) & $463(98.1)$ & $466(98.5)$ & $155(99.4)$ & $203(98.5)$ \\
\hline \multicolumn{6}{|l|}{ Marital status } \\
\hline Single & $123(9.4)$ & $52(11.1)$ & $49(10.4)$ & $11(7.1)$ & $11(5.3)$ \\
\hline Married & $920(70.5)$ & 321 (68.3) & $330(69.8)$ & $115(73.7)$ & $154(74.8)$ \\
\hline $\begin{array}{l}\text { Stable relationship not } \\
\text { married }\end{array}$ & $261(20.0)$ & $97(20.6)$ & $94(19.9)$ & $29(18.6)$ & $41(19.9)$ \\
\hline \multicolumn{6}{|l|}{ Sex of baby } \\
\hline Male & $666(51.0)$ & $221(47.0)$ & $252(53.3)$ & $81(51.9)$ & $112(54.4)$ \\
\hline Female & $639(49.0)$ & $249(53.0)$ & $221(46.7)$ & $75(48.1)$ & $94(45.6)$ \\
\hline Pre-eclampsia & $48(3.7)$ & $17(3.6)$ & $7(1.5)$ & $16(10.3)$ & $9(4.4)$ \\
\hline $\begin{array}{l}\text { Birth weight }(\mathrm{g}) \text {, median } \\
\text { IQR }\end{array}$ & 3460 (3160-3770) & 3400 (3120-3690) & $3510(3200-3800)$ & 3345 (2915-3670) & $3650(3300-4000)$ \\
\hline Macrosomia (>4000 g) & $169(13.0)$ & $32(6.8)$ & $65(13.7)$ & $21(13.5)$ & $51(24.8)$ \\
\hline \multicolumn{6}{|l|}{$\begin{array}{l}\text { Baby size according to } \\
\text { customised centile }\end{array}$} \\
\hline SGA $<10$ th centile & $135(10.3)$ & $59(12.6)$ & $40(8.5)$ & $22(14.1)$ & $14(6.8)$ \\
\hline $\begin{array}{l}\text { AGA } \geq 10 \text { th } \\
\text { centile } \leq 90 \text { th centile }\end{array}$ & $1027(78.7)$ & $383(81.5)$ & $374(79.1)$ & $110(70.5)$ & $160(77.7)$ \\
\hline LGA>90th centile & $143(11.0)$ & $28(6.0)$ & $59(12.5)$ & $24(15.4)$ & $32(15.5)$ \\
\hline \multicolumn{6}{|l|}{$\begin{array}{l}\text { Body composition (at } \\
2 \text { months) }\end{array}$} \\
\hline Body fat (\%), mean SD & $21.8( \pm 4.3)$ & $21.8( \pm 4.3)$ & $21.6( \pm 4.4)$ & $22.3( \pm 4.6)$ & $21.6( \pm 4.2)$ \\
\hline Missing & $272(20.8)$ & $98(20.9)$ & $93(19.7)$ & $39(25.0)$ & $42(20.4)$ \\
\hline \multicolumn{6}{|l|}{ BMI $\left(\mathrm{kg} / \mathrm{m}^{2}\right)$ at 2 years $\ddagger$} \\
\hline Thin & $77(5.9)$ & $28(6.0)$ & $34(7.2)$ & $6(3.8)$ & $9(4.4)$ \\
\hline Normal & $812(62.2)$ & $289(61.5)$ & $286(60.5)$ & $101(64.7)$ & $136(66.0)$ \\
\hline Overweight & $96(7.4)$ & $29(6.2)$ & $39(8.2)$ & $12(7.7)$ & $16(7.8)$ \\
\hline Obese & $10(0.8)$ & $4(0.9)$ & $2(0.4)$ & $3(1.9)$ & $1(0.5)$ \\
\hline
\end{tabular}




\begin{tabular}{|c|c|c|c|c|c|}
\hline Characteristic & $\begin{array}{l}\text { Overall } \\
\text { n (\%) }\end{array}$ & $\begin{array}{l}\text { Unassisted vaginal } \\
\text { n (\%) }\end{array}$ & $\begin{array}{l}\text { Operative vaginal * } \\
\text { n (\%) }\end{array}$ & $\begin{array}{l}\text { Prelabour LSCS } \\
\text { n (\%) }\end{array}$ & $\begin{array}{l}\text { LSCS in labour } \\
\mathrm{n}(\%)\end{array}$ \\
\hline \multicolumn{6}{|c|}{ BMI $\left(\mathrm{kg} / \mathrm{m}^{2}\right)$ at 5 years $\neq$} \\
\hline Thin & $38(2.9)$ & $13(2.8)$ & $17(3.6)$ & $3(1.9)$ & $5(2.4)$ \\
\hline Obese & $21(1.6)$ & $10(2.1)$ & $6(1.3)$ & $3(1.9)$ & $2(1.0)$ \\
\hline Missing & $493(37.8)$ & $189(40.2)$ & $176(37.2)$ & 55 (35.3) & $73(35.4)$ \\
\hline
\end{tabular}

*Vacuum or forceps.

†Total years of schooling (primary and secondary, not preschool or tertiary).

†International Obesity Task Force age and sex-specific cut-offs.

AGA, appropriate for gestational age; BMI, body mass index; LSCS, lower segment caesarean section; SGA, small for gestational age; LGA, large for gestational age.

unavailable; this variable attenuated effect size estimates towards the null ${ }^{12}$ in previous studies. BMI at 15 weeks' gestation, a good proxy for pre-pregnancy BMI, was used because 15 weeks is prior to the occurrence of most weight gain in pregnancy. It has been suggested that any association between CS birth and childhood obesity is due to antibiotics administered during CS, with CS delivery serving as a proxy; nonetheless, this proposition has not been supported by evidence. ${ }^{37} 38$ The major limitation was the low number of cases at 2 and 5 years of age.

\section{Interpretation}

The relationship between CS delivery and offspring being overweight or obese has been explored by several systematic reviews and meta-analyses. ${ }^{12} 141539$ A positive association was the most common finding. Our findings are similar to those of infants, born in 2010, from a Danish prospective cohort study which found that the largest BMI difference by delivery mode, from birth to 5 years of age, occurred at 6 months' age and that this difference did not track into later childhood at age

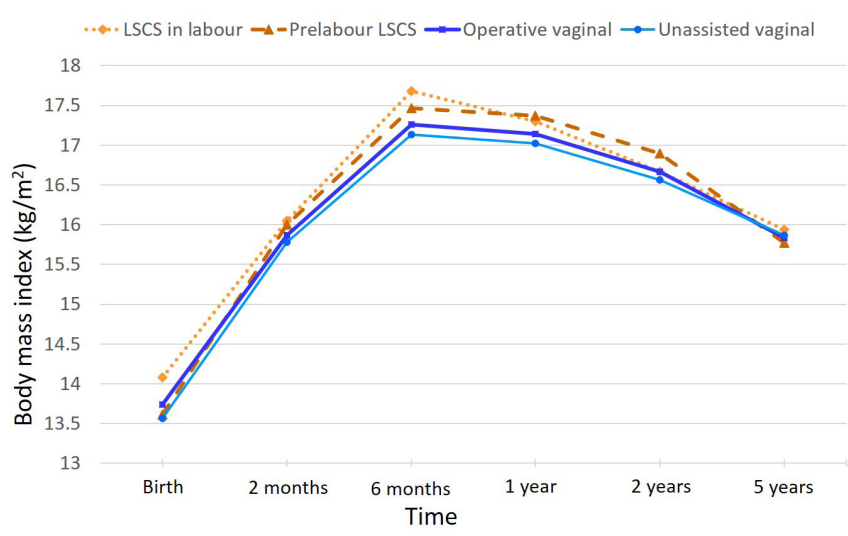

Figure 1 Mean BMI from birth to 5 years of age: Please note that the time axis has been expanded below age 1 year to permit clearer visualisation. BMI, body mass index; LSCS, lower segment caesarean section.
5 years. ${ }^{38}$ In addition, similar to this study, no significant difference in $\mathrm{BF} \%$ by delivery mode was found. It is worth highlighting that the first 2 years of life have been identified as a critical developmental window during which perturbations in growth and development are more likely to result in lifelong sequelae. ${ }^{40}$ This Danish study, like ours and also as reported by the systematic reviews and meta-analyses, ${ }^{13} 32$ did not find a sex-specific growth pattern by mode of birth. This suggests that in humans CS birth might not influence sex-specific growth patterns as has been observed in mouse studies. $^{25}$

Childhood fat mass index data from a Brazilian longitudinal cohort also showed no significant difference between children born by CS and VD at 6 years of age. ${ }^{41}$ The declining influence of CS birth on the risk of obesity as children grow older has been attributed to the increasing influence of other risk factors for obesity like physical inactivity, family dietary habits, watching television (and the use of other electronic devices). ${ }^{42}$ Indeed, a study which utilised a sibling-pair design attributed the

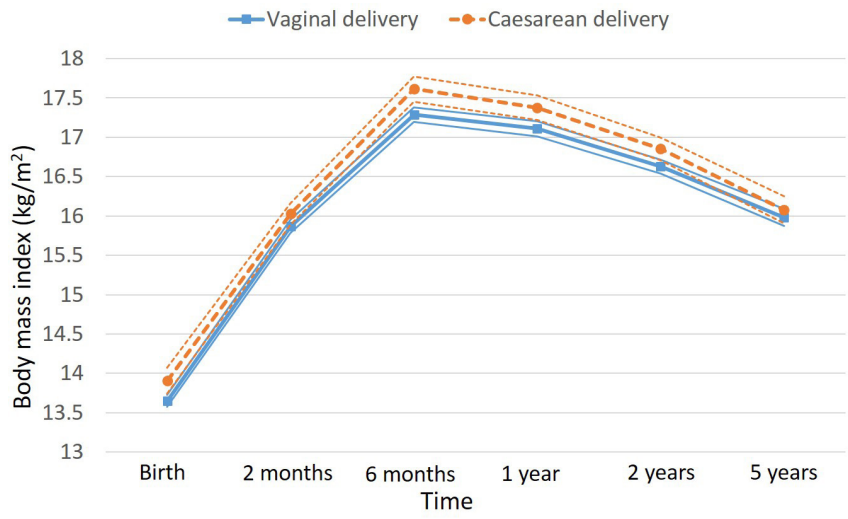

Figure 2 Mean BMI from birth to 5 years of age with $95 \%$ confidence intervals (Cls) around the mean BMI-thin lines. There is no overlap of the $95 \% \mathrm{Cls}$ at 6 months of age. Please note that the time axis has been expanded below age 1 year to allow clearer visualisation. BMI, body mass index . 
Table 2 Mode of delivery and body fat per cent at age 2 months

\begin{tabular}{llllll}
\hline Delivery mode & Cases & & & \\
\cline { 2 - 4 } & $\mathbf{n}$ & Coef. $(\mathbf{9 5 \%} \mathbf{C l})$ & P value & AdjCoef. (95\% Cl)* & P value \\
\hline Unassisted vaginal & 372 & Reference & & Reference \\
Operative vaginal & 380 & $-0.16(-0.78$ to 0.46$)$ & 0.614 & $-0.10(-0.72$ to 0.52$)$ & 0.743 \\
Prelabour LSCS & 117 & $0.50(-0.40$ to 1.40$)$ & 0.278 & $0.46(-0.46$ to 1.40$)$ & 0.325 \\
LSCS in labour & 164 & $-0.19(-0.9$ to 0.61$)$ & 0.642 & $0.07(-0.88$ to 0.73$)$ & 0.864 \\
\hline
\end{tabular}

$\mathrm{N}$ for adjusted model=1033. Linear regression.

${ }^{*}$ Adjusted for maternal age, education, ethnicity, marital status, infant sex, maternal smoking during pregnancy, maternal BMI at the first antenatal visit, gestational age (at delivery), birth weight and pre-eclampsia

Adj, adjusted; BMI, body mass index; Coef, $\beta$-coefficient; LSCS, lower segment caesarean section.

observed association between CS birth and childhood obesity to unmeasured confounding. ${ }^{43}$

Our results are dissimilar to those of children from a Boston, United States (US) cohort study which found a positive association between delivery mode and being overweight or obese at age 5 years. ${ }^{37}$ The Boston study, unlike ours, did not subclassify CS births into elective and emergency for example, and unusually there were more girls delivered by $\mathrm{CS},{ }^{44}$ this might indicate reduced external validity for the US study.

A few studies have been able to differentiate between elective/prelabour CS and emergency/LSCS in labour and they have been limited by small sample sizes. ${ }^{16} 17$ However, a higher risk of childhood obesity for infants born by emergency CS than elective CS was reported. ${ }^{17}$ Finding an association at age 5 years between LSCS in labour, when membranes are more likely to have ruptured, and being overweight or obese, but not with prelabour CS suggests an attenuated role for vaginal flora in the genesis of children being overweight or obese. A possible explanation for the LSCS in labour association is confounding by the indications for CS.
The exact indications for CS were not available for this cohort. However, a divergent BMI trajectory in mid-infancy which then converges by age 5 years between VD and CS babies may suggest a transient role for the vaginal microflora. Further exploration, around mid-infancy, of the association between CS birth and BMI is required.

The CS rate of $27.8 \%$, in this cohort, is consistent with published national estimates of $27.1 \%$ to $28.6 \%$ that prevailed during the study's recruitment period from 2007 to $2011 .^{45}$ This suggests the generalizability of findings to the Irish population, particularly 'low-risk' first-time mothers. A macrosomia ( $>4000 \mathrm{~g})$ prevalence of $13.0 \%$ is almost double that of another high-income country, the USA at $7.5 \%$ during a similar time period, and suggests high baseline Irish rates of excess adiposity. ${ }^{46}$ The general Irish population had at age 3 and 5 years a prevalence of $24 \%$ and $20 \%$, respectively, for obesity and being overweight ${ }^{47}$ which is higher than that observed in this cohort. This cohort's low-risk population likely explains its lower prevalence of being overweight or obese compared with the general Irish population.

Table 3 Mode of delivery and body mass index at age 2 years

\begin{tabular}{|c|c|c|c|c|c|}
\hline \multirow[b]{2}{*}{ BMI category (normal BMI-base outcome) } & \multirow{2}{*}{$\begin{array}{l}\text { Cases } \\
\mathrm{n}\end{array}$} & \multirow[b]{2}{*}{ RRR (95\% Cl) } & \multirow[b]{2}{*}{$P$ value } & \multirow[b]{2}{*}{ AdjRRR $(95 \% \mathrm{Cl})^{*}$} & \multirow[b]{2}{*}{$P$ value } \\
\hline & & & & & \\
\hline \multicolumn{6}{|l|}{ Thin } \\
\hline Unassisted vaginal & 30 & Reference & & Reference & \\
\hline Operative vaginal & 37 & $1.23(0.74$ to 2.05$)$ & 0.417 & $1.42(0.83$ to 2.41$)$ & 0.199 \\
\hline Prelabour LSCS & 6 & $0.59(0.24$ to 1.47$)$ & 0.259 & 0.65 (0.26 to 1.62$)$ & 0.352 \\
\hline LSCS in labour & 9 & 0.65 (0.30 to 1.41$)$ & 0.279 & $0.86(0.39$ to 1.87$)$ & 0.696 \\
\hline \multicolumn{6}{|l|}{ Overweight or obese } \\
\hline Unassisted vaginal & 37 & Reference & & Reference & \\
\hline Operative vaginal & 41 & 1.11 (0.69 to 1.78$)$ & 0.67 & 0.95 (0.58 to 1.56$)$ & 0.853 \\
\hline Prelabour LSCS & 17 & 1.45 (0.79 to 2.65$)$ & 0.233 & 1.38 (0.73 to 2.62$)$ & 0.324 \\
\hline LSCS in labour & 20 & $1.18(0.66$ to 2.10$)$ & 0.583 & 0.88 (0.48 to 1.61$)$ & 0.68 \\
\hline
\end{tabular}

$\mathrm{N}$ for adjusted model=1062. Multinomial logistic regression.

${ }^{*}$ Adjusted for maternal age, education, ethnicity, marital status, infant sex, maternal smoking during pregnancy, maternal BMI at the first antenatal visit, gestational age (at delivery), birth weight and pre-eclampsia.

Adj, adjusted; BMI, body mass index; LSCS, lower segment caesarean section; RRR, relative risk ratio. 
Table 4 Mode of delivery and body mass index at age 5 years

\begin{tabular}{|c|c|c|c|c|c|}
\hline \multirow[b]{2}{*}{ BMI category (normal BMI-base outcome) } & \multirow{2}{*}{$\begin{array}{l}\text { Cases } \\
\mathbf{n}\end{array}$} & \multirow[b]{2}{*}{$\operatorname{RRR}(95 \% \mathrm{Cl})$} & \multirow[b]{2}{*}{$\mathbf{P}$ value } & \multirow[b]{2}{*}{ AdjRRR $(95 \% \mathrm{Cl}) *$} & \multirow[b]{2}{*}{ P value } \\
\hline & & & & & \\
\hline \multicolumn{6}{|l|}{ Thin } \\
\hline Operative vaginal & 18 & 1.45 (0.69 to 3.02$)$ & 0.324 & $1.82(0.84$ to 3.96$)$ & 0.131 \\
\hline Prelabour LSCS & 3 & $0.68(0.19$ to 2.44$)$ & 0.553 & $0.46(0.14$ to 1.56$)$ & 0.212 \\
\hline \multicolumn{6}{|l|}{ Overweight or obese } \\
\hline Unassisted vaginal & 36 & Reference & & Reference & \\
\hline Operative vaginal & 52 & $1.51(0.95$ to 2.40$)$ & 0.079 & 1.64 (1.00 to 2.67$)$ & 0.05 \\
\hline Prelabour LSCS & 17 & $1.39(0.74$ to 2.60$)$ & 0.305 & $1.37(0.69$ to 2.69$)$ & 0.368 \\
\hline LSCS in labour & 26 & $1.61(0.93$ to 2.80$)$ & 0.09 & $1.69(0.92$ to 3.08$)$ & 0.09 \\
\hline
\end{tabular}

$\mathrm{N}$ for adjusted model=856. Multinomial logistic regression.

*Adjusted for maternal age, education, ethnicity, marital status, infant sex, maternal smoking during pregnancy, maternal BMI at the first antenatal visit, gestational age (at delivery), birth weight and pre-eclampsia.

Adj, adjusted; BMI, body mass index; LSCS, lower segment caesarean section; RRR, relative risk ratio.

\section{CONCLUSION}

We have found no evidence to support a relationship between prelabour CS and offspring being overweight or obese in early childhood. No significant differences in outcome at 2 months and 2 years, and an increased risk of being overweight or obese in children born by CS in labour, but not prelabour CS at 5 years, suggests that the previously hypothesised causal effects due to vaginal microflora are also unlikely at least in the long term.

\section{Author affiliations}

${ }^{1}$ The Irish Centre for Fetal and Neonatal Translational Research (INFANT), University College Cork, Cork, Ireland

${ }^{2}$ Department of Obstetrics and Gynaecology, University College Cork, Cork, Ireland ${ }^{3}$ Department of Women and Children's Health, School of Life Course Sciences, King's College London, London, United Kingdom

${ }^{4}$ College of Life Sciences, University of Leicester, Leicester, United Kingdom ${ }^{5}$ Department of Women's and Children's Health, Faculty of Health and Life Sciences, University of Liverpool, Liverpool, United Kingdom

${ }^{6}$ Centre for Longitudinal Research - He Ara ki Mua, University of Auckland, Auckland, New Zealand

${ }^{7}$ Department of Paediatrics and Child Health, University College Cork, Cork, Ireland ${ }^{8}$ School of Public Health, University College Cork, Cork, Ireland

Acknowledgements We are grateful to the pregnant women who agreed to participate in the SCOPE study. We thank mothers who permitted their new-born infants to participate in the BASELINE study.

Contributors GM, FPM, PNB, LCK, SMBM, DMM, JOH and ASK conceived and designed the study. GM and ASK analysed the data and all authors interpreted the results. GM wrote the first draft of the article and FPM, PNB, LCK, SMBM, DMM, JOH and ASK revised it critically for important intellectual content. All authors approved the final version and agree to be accountable for all aspects of the work.

Funding SCOPE Ireland was supported by the Health Research Board, Ireland (CSA 2007/2). The BASELINE cohort was funded by the National Children's Research Centre, Dublin, Ireland, and the Food Standards Agency of the United Kingdom (grant no. T07060). GM is supported by the Irish Centre for Fetal and Neonatal Translational Research (INFANT) (grant no. 12/RC/2272). The other authors report no support relevant to this article.

Competing interests None declared.

Patient consent for publication Not required.
Ethics approval Clinical Research Ethics Committee of the Cork Teaching Hospitals (Ref: ECM5 (9) 01/07/2008.

Provenance and peer review Not commissioned; externally peer reviewed.

Data sharing statement Data may be accessed by request from the Babies After SCOPE: Evaluating the Longitudinal Impact on Neurological and Nutritional Endpoints (BASELINE) study. Contact details are available on the study website http://www.baselinestudy.net/.

Open access This is an open access article distributed in accordance with the Creative Commons Attribution Non Commercial (CC BY-NC 4.0) license, which permits others to distribute, remix, adapt, build upon this work non-commercially, and license their derivative works on different terms, provided the original work is properly cited, appropriate credit is given, any changes made indicated, and the use is non-commercial. See: http://creativecommons.org/licenses/by-nc/4.0/.

\section{REFERENCES}

1. Betrán AP, Ye J, Moller AB, et al. The increasing trend in caesarean section rates: global, regional and national estimates: 1990-2014. PLoS One 2016;11:e0148343.

2. Lundgren I, Healy $P$, Carroll M, et al. Clinicians' views of factors of importance for improving the rate of VBAC (vaginal birth after caesarean section): a study from countries with low VBAC rates. BMC Pregnancy Childbirth 2016;16:350.

3. Betran AP, Torloni MR, Zhang JJ, et al. WHO statement on caesarean section rates. BJOG 2016;123:667-70.

4. Organisation for Economic Co-operation and Development. Health at a glance: OECD indicators, 2015.

5. Lutomski JE, Murphy M, Devane D, et al. Private health care coverage and increased risk of obstetric intervention. BMC Pregnancy Childbirth 2014;14:13.

6. Kenny LC, Lavender T, McNamee R, et al. Advanced maternal age and adverse pregnancy outcome: evidence from a large contemporary cohort. PLoS One 2013;8:e56583.

7. Minkoff $H$. Fear of litigation and cesarean section rates. Semin Perinatol 2012;36:390-4.

8. Mylonas I, Friese K. Indications for and risks of elective cesarean section. Dtsch Arztebl Int 2015;112:489-95.

9. Hull HR, Dinger MK, Knehans AW, et al. Impact of maternal body mass index on neonate birthweight and body composition. Am J Obstet Gynecol 2008;198:416.e1-6.

10. McCarthy FP, Khashan AS, Murray D, et al. Parental physical and lifestyle factors and their association with newborn body composition. BJOG 2016;123:1824-9.

11. Barker DJ, Osmond C, Golding J, et al. Growth in utero, blood pressure in childhood and adult life, and mortality from cardiovascular disease. BMJ 1989;298:564-7. 
12. Kuhle S, Tong OS, Woolcott CG. Association between caesarean section and childhood obesity: a systematic review and metaanalysis. Obes Rev 2015;16:295-303.

13. Sutharsan R, Mannan M, Doi SA, et al. Caesarean delivery and the risk of offspring overweight and obesity over the life course: a systematic review and bias-adjusted meta-analysis. Clin Obes 2015;5:293-301.

14. Darmasseelane K, Hyde MJ, Santhakumaran S, et al. Mode of delivery and offspring body mass index, overweight and obesity in adult life: a systematic review and meta-analysis. PLoS One 2014;9:e87896.

15. Keag OE, Norman JE, Stock SJ. Long-term risks and benefits associated with cesarean delivery for mother, baby, and subsequent pregnancies: Systematic review and meta-analysis. PLoS Med 2018;15:e1002494.

16. Blustein J, Attina T, Liu M, et al. Association of caesarean delivery with child adiposity from age 6 weeks to 15 years. Int $\mathrm{J}$ Obes 2013;37:900-6

17. Huh SY, Rifas-Shiman SL, Zera CA, et al. Delivery by caesarean section and risk of obesity in preschool age children: a prospective cohort study. Arch Dis Child 2012;97:610-6.

18. Bouhanick B, Ehlinger V, Delpierre C, et al. Mode of delivery at birth and the metabolic syndrome in midlife: the role of the birth environment in a prospective birth cohort study. BMJ Open 2014;4:e005031.

19. Rehbinder EM, Lødrup Carlsen KC, Staff AC, et al. Is amniotic fluid of women with uncomplicated term pregnancies free of bacteria? Am J Obstet Gynecol 2018;219:289.e1-12.

20. Turnbaugh PJ, Ley RE, Mahowald MA, et al. An obesity-associated gut microbiome with increased capacity for energy harvest. Nature 2006;444:1027-31.

21. Jumpertz R, Le DS, Turnbaugh PJ, et al. Energy-balance studies reveal associations between gut microbes, caloric load, and nutrient absorption in humans. Am J Clin Nutr 2011:94:58-65.

22. Tun HM, Bridgman SL, Chari R, et al. Roles of birth mode and infant gut microbiota in intergenerational transmission of overweight and obesity from mother to offspring. JAMA Pediatr 2018;172:368.

23. Chu DM, Ma J, Prince AL, et al. Maturation of the infant microbiome community structure and function across multiple body sites and in relation to mode of delivery. Nat Med 2017;23:314-26.

24. Stinson LF, Payne MS, Keelan JA. A Critical review of the bacterial baptism hypothesis and the impact of cesarean delivery on the infant microbiome. Front Med 2018;5.

25. Martinez KA, Devlin JC, Lacher CR, et al. Increased weight gain by C-section: functional significance of the primordial microbiome. Sci Adv 2017;3:eaao1874.

26. McCowan LNR, Taylor R. ACTRN12607000551493: Australian New Zealand Clinical Trials Registry. 2007 https://www.anzctr.org.au/Trial/ Registration/TrialReview.aspx?id=82254

27. O'Donovan SM, Murray DM, Hourihane JO, et al. Cohort profile: the Cork baseline birth cohort study: babies after scope: evaluating the longitudinal impact on neurological and nutritional endpoints. Int $J$ Epidemiol 2015;44:764-75.

28. Fomon SJ, Haschke F, Ziegler EE, et al. Body composition of reference children from birth to age 10 years. Am J Clin Nutr 1982:35:1169-75
29. O'Neill SM, Hannon G, Khashan AS, et al. Thin-for-gestational age infants are at increased risk of neurodevelopmental delay at 2 years. Arch Dis Child Fetal Neonatal Ed 2017;102:F197-202.

30. Cole TJ, et al. Establishing a standard definition for child overweight and obesity worldwide: international survey. BMJ 2000;320:1240-3.

31. Cole TJ, Flegal KM, Nicholls D, et al. Body mass index cut offs to define thinness in children and adolescents: international survey. BMJ 2007;335:194.

32. HT L, Zhou YB, Liu JM. The impact of cesarean section on offspring overweight and obesity: a systematic review and meta-analysis. International journal of obesity 2013;37:893-9.

33. Yuan C, Gaskins AJ, Blaine Al, et al. Association between cesarean birth and risk of obesity in offspring in childhood, adolescence, and early adulthood. JAMA Pediatr 2016;170:e162385.

34. Sinnott S-J, Brick A, Layte R, et al. National variation in caesarean section rates: a cross sectional study in Ireland. PLoS One 2016;11:e0156172.

35. Magriplis E, Farajian P, Panagiotakos DB, et al. Maternal smoking and risk of obesity in school children: Investigating early life theory from the GRECO study. Prev Med Rep 2017;8:177-82.

36. An Phríomh-Oifig Staidrimh -Central Statistics Office. Census of population 2016 - profile 8 irish travellers, ethnicity and religion 2017. $2017 \mathrm{http}: / /$ www.cso.ie/en/releasesandpublications/ep/p-cp8iter/ p8iter/p8e/.

37. Mueller NT, Mao G, Bennet WL, et al. Does vaginal delivery mitigate or strengthen the intergenerational association of overweight and obesity? Findings from the boston birth cohort. Int $J$ Obes 2017;41:497-501.

38. Vinding RK, Sejersen TS, Chawes BL, et al. Cesarean delivery and body mass index at 6 months and into childhood. Pediatrics 2017;139:e20164066.

39. Kuhle S, Woolcott CG. Caesarean section is associated with offspring obesity in childhood and young adulthood. Evid Based Med 2017;22:111.

40. Barker DJ. Sir Richard Doll Lecture. Developmental origins of chronic disease. Public health 2012;126:185-9.

41. Barros AJ, Santos LP, Wehrmeister F, et al. Caesarean section and adiposity at 6,18 and 30 years of age: results from three Pelotas (Brazil) birth cohorts. BMC Public Health 2017:17:256.

42. Pei Z, Heinrich J, Fuertes E, et al. Cesarean delivery and risk of childhood obesity. J Pediatr 2014;164:1068-73.

43. Rifas-Shiman SL, Gillman MW, Hawkins SS, et al. Association of cesarean delivery with body mass index $z$ score at age 5 years. JAMA Pediatr 2018;172:777.

44. Eogan MA, Geary MP, O'Connell MP, et al. Effect of fetal sex on labour and delivery: retrospective review. BMJ 2003:326:137.

45. Healthcare Pricing Office. Perinatal Statistics Report. Health service executive, 2017

46. Martin JA, Hamilton BE, Ventura SJ, et al. Births: final data for 2009. National vital statistics reports: from the Centers for Disease Control and Prevention, National Center for Health Statistics, National Vital Statistics System. 2011;60:1-70.

47. Growing Up in Ireland. Key findings: infant cohort (at 5 years). 2013. 